\title{
ASTHMA IN YOUNG AND ELDERLY: THE DIFFERENCES
}

\author{
Kishan J, Garg K \\ Department of Tuberculosis and Chest Diseases, Government Medical College, Patiala, Punjab, India
}

\begin{abstract}
Introduction: Asthma is considered as disease of childhood but may continue in elderly or elderly may be diagnosed as asthmatic for the first time. Asthma in elderly may differ from young with respect to diagnosis and management on account of psychosocial and economic differences and age related changes which may further be enhanced because of comorbidities and interactions between the drugs used for comorbidities.
\end{abstract}

Methodology: Young and elderly asthmatics were compared with regards to Symptoms, Severity (Global Initiative for Asthma: GINA guidelines), Accessibility to treatment, Co-morbidities, Inhalational techniques, Compliance and factors affecting compliance and; Outcome measures. These patients were followed up periodically for above said parameters.

Results: Salient differences noted in elderly vs young were: higher GINA scoring (Moderate Persistent: $30 \%$ vs $10 \%$ ), baseline non-compliance ( $60 \%$ vs $30 \%$ ), non-compliance due to cost and memory ( $80 \%$ vs $26.7 \%$ ), incorrect technique of inhalation ( $69.6 \%$ vs $42.4 \%$ ), comorbidities ( $98 \%$ vs $38 \%$ ) and concomitant drug usage $(68 \%$ vs $40 \%)$. There were differences in symptoms and quality of life indicators. There was significant improvement in various parameters in both groups, especially the young if counseled properly.

Conclusion: Significant differences exist between elderly and young asthmatics.

Key words: Asthma, Young, Elderly

\section{INTRODUCTION}

Asthma is considered as a disease of childhood, but it may be first diagnosed in elderly. Although most elderly patients have long-standing asthma, some may have (late-onset disease). Late-onset asthma patients usually present with moderate to severe symptoms. ${ }^{1}$ Some studies have shown that $40 \%$ elderly have their first asthmatic attack after 40 years. $^{2}$

\section{Correspondence:}

Dr. Jai Kishan Karahyla

Director

Research \& Medical Education \& STDC Punjab

Dept. of TB \& Chest Diseases

Government Medical College

Patiyala, Punjab, India.
Asthma in elderly has a major impact on patient's quality of life. It is under diagnosed and under treated.

Asthma may differ in young and elderly from beginning to final outcomes. The study was conducted to make comparisons of the following parameters in asthma in elderly ( $\geq 65 \mathrm{yrs}$ ) and younger ( $<40 \mathrm{yrs}$ ) patients.

1. Symptoms.

2. Severity (GINA guidelines).

3. Accessibility to treatment.

4. Co-morbidities.

5. Treatment methods especially inhalational techniques.

6. Treatment compliance and factors affecting compliance.

7. Outcome measures like quality of life, asthma exacerbations etc. 


\section{METHODOLOGY}

Study Design: The study was a prospective study conducted on patients of bronchial asthma presenting to the Department of Tuberculosis and Chest Diseases, Government Medical College, Patiala, India and fulfilling the following diagnostic criteria:

History suggestive of asthma like attacks of cough, wheezing, or exercise induced dyspnoea or nocturnal cough or wheezing and evidence of bronchial reversibility on spirometery.

Sample size: 100 patients of bronchial asthma were studied and were divided into:-

Group A: 50 patients $\geq 65$ yrs.

Group B: 50 patients $<40$ yrs.

Detailed personal history of the patient including age, sex, detailed clinical history including history of cough, wheezing, history of past illness including history of atopy, history of emergency admissions/ hospitalizations, type of medications used, routes of administration and inhalational technique was taken. The details of treating physicians, compliance and causes for non compliance, adverse effects of asthma medications, any concomitant drug usage, presence of any confidante and frequency of contact with him/her, associated co-morbid conditions and quality of life indicators were also studied. Patients were followed up at $15^{\text {th }}$ day, $1^{\text {st }}, 2^{\text {nd }}$ and $3^{\text {rd }}$ month. At each follow up, questionnaire based symptomatic improvements or deteriorations, type of medications, routes of drug delivery, inhalational techniques and compliance were noted. PEFR (Peak Expiratory Flow Rate) testing was also done at each visit. The data so obtained was tabulated and statistically analyzed using the Chi-Square or the Fisher's Exact Test.

Patients between 40-65 year age group were not included so as to avoid confounding and to represent a purely young and purely elderly population so that the differences, if any, can be found.
Informed consent was obtained from all the patients.

Ethical clearance was obtained from the medical college and the state medical university.

\section{RESULTS}

Both groups were comparable with regards to gender, rural urban background and marital status, except that death of spouse was significantly higher in elderly. Symptoms were significantly more predominant in elderly and history of atopy was significantly more in young.

Table 1. Demographic and Symptomatic Profile

\begin{tabular}{|l|l|l|l|}
\hline & $\begin{array}{l}\text { Elderly } \\
(\mathrm{n}=50)\end{array}$ & $\begin{array}{l}\text { Young } \\
(\mathrm{n}=50)\end{array}$ & P value \\
\hline Sex & 26 & 34 & 0.102 \\
\hline Males & 24 & 16 & 0.102 \\
\hline Females & \multicolumn{5}{|l|}{} \\
\hline Background & \multicolumn{5}{|l|}{} \\
\hline Rural & 24 & 31 & 0.159 \\
\hline Urban & 26 & 19 & 0.159 \\
\hline Marital status & 32 & 38 & 0.191 \\
\hline Married & 0 & 11 & $<0.001$ \\
\hline Unmarried & 0 & $<0.001$ \\
\hline Spouse dead & 18 & 1 & 0.006 \\
\hline Symptoms & 19 & 7 & 0.002 \\
\hline Daily cough & 19 & 0.004 \\
\hline Wheezing & 18 & 5 & $<0.001$ \\
\hline History of atopy & 29 & 42 & $<0.001$ \\
\hline Age at onset & 8 & 50 & 0 \\
\hline$<40 y e a r s$ & 82 & 0 &
\end{tabular}

As per GINA guidelines, moderate persistent and both moderate and severe persistent asthma was significantly higher in elderly. Significantly more young received care from pulmonologist and were prescribed inhalational therapy.

(DPI: Dry Powder Inhaler, MDI: Metered Dose Inhaler, MDIS: Metered Dose Inhaler with Spacer) 


\begin{tabular}{|c|c|c|}
\hline & Elderly & Young \\
\hline \multicolumn{3}{|l|}{ GINA Guidelines } \\
\hline Intermittent & $16(32 \%)$ & $23(46 \%)$ \\
\hline Mild Persistent & $15(30 \%)$ & $20(40 \%)$ \\
\hline Moderate Persistent & $15(30 \%)$ & $5(10 \%)$ \\
\hline Intermitenet Persistent & $4(8 \%)$ & $2(4 \%)$ \\
\hline \multicolumn{3}{|l|}{ Treating Physician } \\
\hline Pulmonologist & $16(32 \%)$ & $27(54 \%)$ \\
\hline General Physician & $21(42 \%)$ & $15(30 \%)$ \\
\hline $\begin{array}{l}\text { Alternate System of } \\
\text { Medication }\end{array}$ & $4(8 \%)$ & $3(6 \%)$ \\
\hline Quack & $9(18 \%)$ & $5(10 \%)$ \\
\hline \multicolumn{3}{|l|}{ Inhalational Therapy } \\
\hline Pulmonologist & $16(32 \%)$ & $27(54 \%)$ \\
\hline General Physician & $7(14 \%)$ & $6(36 \%)$ \\
\hline $\begin{array}{l}\text { Alternate System of } \\
\text { Medication }\end{array}$ & 0 & 0 \\
\hline Quack & 0 & 0 \\
\hline \multicolumn{3}{|l|}{ Type of Device } \\
\hline DPI & $17(73.9 \%)$ & $26(78.8 \%)$ \\
\hline MDI & $2(8.7 \%)$ & $2(6.1 \%)$ \\
\hline MDIS & $4(17.4 \%)$ & $5(15.1 \%)$ \\
\hline
\end{tabular}

Baseline compliance and confident and correct usage of inhalational devices was significantly higher in young. Statistically significant higher non compliance was present in elderly which was due to cost and poor memory.

Elderly had significantly higher number of comorbidities, especially hypertension, visual impairment, depressive symptoms and osteoarthiritis resulting in significantly higher number of concomitant drug usage. Elderly also had poorer contact with the confidante and impaired quality of life, fatigue and impaired social functioning.

Table 4. Comorbidities, Concomitant other drug usage and Quality of Life parameters

\begin{tabular}{|c|c|c|c|}
\hline & Elderly & Young & $P$ value \\
\hline \multicolumn{4}{|c|}{ Number of comorbidities } \\
\hline 0 & $1(2 \%)$ & $31(62 \%)$ & $<0.001$ \\
\hline 1 & $12(24 \%)$ & $11(22 \%)$ & 0.806 \\
\hline 2 & $9(18 \%)$ & $5(10 \%)$ & 0.249 \\
\hline 3 & $11(22 \%)$ & & \\
\hline
\end{tabular}

Table 3. Baseline Compliance and Usage of Inhalational Therapy

\begin{tabular}{|l|l|l|l|}
\hline & Elderly & Young & P value \\
\hline $\begin{array}{l}\text { Baseline } \\
\text { Compliance }\end{array}$ & $20(40 \%)$ & $35(70 \%)$ & $<0.001$ \\
\hline Reasons for non compliance & \multicolumn{3}{|l|}{} \\
\hline Cost & $6(20 \%)$ & $4(26.7 \%)$ & 0.709 \\
\hline $\begin{array}{l}\text { Cost \& Poor } \\
\text { Memory }\end{array}$ & $7(23.3 \%)$ & 0 & 0.001 \\
\hline Poor Memory & $11(36.7 \%)$ & 0 & 0.001 \\
\hline $\begin{array}{l}\text { Relief of } \\
\text { Symptoms }\end{array}$ & $6(20 \%)$ & $11(73.3 \%)$ & 0.709 \\
\hline $\begin{array}{l}\text { Baseline use } \\
\text { of Inhalational } \\
\text { therapy }\end{array}$ & $23(46 \%)$ & $33(66 \%)$ & 0.044 \\
\hline
\end{tabular}

Technique of Inhalation

\begin{tabular}{|l|l|l|l|}
\hline $\begin{array}{l}\text { Confident and } \\
\text { Demonstrate } \\
\text { Correctly }\end{array}$ & $7(30.4 \%)$ & $19(57.6 \%)$ & 0.045 \\
\hline $\begin{array}{l}\text { Confident } \\
\text { but does not } \\
\text { Demonstrate } \\
\text { Correctly }\end{array}$ & $14(60.9 \%)$ & $12(36.4 \%)$ & 0.070 \\
\hline $\begin{array}{l}\text { Neither } \\
\text { Confident Nor } \\
\text { Demonstrate } \\
\text { Correctly }\end{array}$ & $2(8.7 \%)$ & $2(6 \%)$ & 1.000 \\
\hline
\end{tabular}

\section{DISCUSSION}

Elderly had more symptoms which may be because of higher comorbidities and poor control of asthma due to memory and cost constraints. ${ }^{3,4,5,6}$

Although atopy was significantly higher in younger asthmatics, but potential allergens should be avoided in both elderly and young asthmatics. ${ }^{2,3}$

Although asthma in elderly may be a continuum of young age, ${ }^{7,8}$ but in present study $84 \%$ patients had onset after age of 40 years. So diagnosis of asthma in elderly without history of asthma in early childhood should be kept in mind.

Elderly patients had more severe disease than young, this is similar to study by Barr'. Elderly patients had higher GINA gradation (moderate persistent asthma and both moderate and severe persistent asthma taken together $(p=0.025))$. This 
can be explained with delay in diagnosis, delay in starting treatmentand inadequate medications, poor inhalational technique, poor compliance because of cost and memory and absence of confidante because of death of spouse in elderly. Despite of having higher symptoms, elderly attributed them to comorbidities rather than asthma. Moreover, elderly may be placed in higher GINA gradation because of low base line lung functions due to natural decline with age. Even young asthmatics who carry their asthma to old age may have higher grading because of poor control for several years causing airway remodeling.

The severity of asthma in these patients may reflect poor family support and loneliness of the patients especially in elderly whose spouse is not alive. Psycho social and financial factors also gain more importance, especially in case of widowed females in Indian setting who are mostly financially dependent.

Elderly had poorer lung function values which were similar to findings of Quadrelli6.

Similar to study by Diette ${ }^{3}$, significantly more young received care from pulmonologist. In India, there is unequal distribution of health care providers with pulmonologists being stationed in specialized centers which were easily accessible to young, but elderly were constrained to get treatment from locally available general physicians, alternate system of medication or quacks because of psychosocial and economic problems. Pulmonologists are more likely to prescribe inhalational medications and educate about disease and treatment.

Receipt of inhalation therapy through care by pulmonologist than by Quack, general physician or alternate system of medication was found to be statistically significant in elderly $(p=0.001)$ and young, similar to study by $\operatorname{Sin}^{9}$. However, young received statistically significant higher inhalational therapy $(p=0.04)$.

Lack of familiarity of evidenced based medicine about asthma in general physicians, alternate system of medication and quacks, who are not keeping themselves updated regarding latest trends in medical care may partly explain this disparity .Although various asthma consensus guidelines have been promulgated, there remains a substantial gap between recommended and actual practices. These practitioners need to be familiarized regarding current guidelines.

Lack of time in a busy OPD or higher cost of pack of inhalational drugs vs. choice of buying oral medications on day to day basis may be the factors for under usage of inhalational therapy.

As in other studies, 5,10 in our study it was seen that baseline use of inhalational therapy was only $46 \%$ amongst elderly and $66 \%$ amongst young. This may be because young are more receptive to physicians advise but elderly are hard to shed their myths regarding inhalational therapy. Out of 44 patients on oral therapy, when started on inhalational therapy, 8 could not sustain when noted at $3^{\text {rd }}$ month, because of cost. This can be taken care by providing inhalational medications free or at subsidized costs in resource poor settings. It has been proved worldwide that inhalational steroids and treatment of asthma is economical because of the lesser emergency room visits, cost of hospitalizations, better quality of life, fewer loss of working days and lesser side effects.

Failure to instruct patients about use of inhalers and their reinforcement decreases compliance..$^{11}$

Young asthmatics were more confident and correctly used the inhalational therapy than elderly $(p=0.045)$. Similar results were seen by Pereira. ${ }^{10}$ Elderly are less confident, have poor memory, poor effort and poor coordination of the various steps. This necessitates the importance of repeated demonstrations by the treating physician for the use of inhalational device at every visit for efficient drug delivery especially in case of elderly. Information dissemination must include verbal instructions, demonstrations and practice sessions and these must be checked periodically.

The presence of comorbidities is relevant with respect to presentation, recognition and management of older patients with asthma. There may be poor perception of symptoms of asthma itself because the patient may under rate symptoms and attribute his symptoms to be because of 
aging or associated co morbid conditions. It is not uncommon, even for the physician to be in a diagnostic dilemma. for the same because the hallmark symptoms of asthma, including shortness of breath, wheeze and cough are non specific and mimicked by other disease such as Congestive Heart Failure, Chronic Obstructive Pulmonary Disease, chronic aspiration, GERD (Gastro Esophageal Reflux Disease) and trachea-bronchial tumour. The high prevalence of comorbidities in our study is similar to other studies. ${ }^{3,6,9,12}$

Higher incidence of GERD can be because GERD is known to trigger exacerbation of bronchial asthma. Asthma can also lead on to GERD because of aerophagia, hyperinflation of lungs and anti asthma medications can cause relaxation of lower esophageal sphincter..$^{13}$ GERD in patients of asthma having $\geq 4$ comorbidities was more and could be medication related.

Higher incidence of hypertension in elderly may be important because these patients can have breathlessness and rhonchi on auscultation. Similarly, a patient of asthma can have breathlessness. It will be judicious clinical practice to rule out asthma in elderly with hypertension and cardiac disease. $^{2}$

In elderly, higher visual impairment can be because of presbyopic and senile changes leading to difficulties with identification of medications. This can be overcome by assigning different colors to reliever/controller medications. ${ }^{2}$

Higher depressive symptoms in elderly may be because of asthma, comorbidities, loneliness and inability to earn or socio psychological problems.

Osteoarthritis, hearing impairment, senile dementia and BHP are the problems related to normal physiological processes of aging, but gain more importance in elderly because of impact of comorbid conditions.

The patient may be already on many medications for comorbidities and adding asthma medications may pose further difficulty in daily medication regimens.
It has been postulated a number of times that GERD in many patients may be due to the excess of the various medications they are already taking. These include the drugs like anticholinergics, smooth muscle relaxants (badrenergic agents, aminophylline, nitrates, calcium channel blockers and phosphodiesterase inhibitors) etc. ${ }^{13}$ This was confirmed from our study, where it was seen that all $(100 \%)$ patients who were already on $\geq 4$ drugs use, complained of GERD ( $p=0.009$ amongst elderly and $p=0.001$ amongst young).

As seen by Pereira ${ }^{10}$, in our study also more of young were compliant in taking their medication than elderly. In our study, relief of symptoms was an important reason for leaving medication in young. Reason may be that in the young, without any comorbid conditions, the symptoms which were only due to asthma disappeared on taking medications but in elderly, symptoms because of other comorbid conditions may persist.

Young had more contact frequency with confidante than elderly. Importance of confidante lies in the fact that if patient can share his/her problems with someone, he/she may have a better quality of life with improvement in disease parameters. The patients who were not having any confidante had more severe disease with more of non compliance and poor quality of life. Similar results were obtained by Adams. ${ }^{12}$ Elderly are more likely to have fewer confidante because they may be more likely to have lost spouse in old age and may not be able to mix with people because of physical, financial and psychological problems.

Poor quality of life amongst elderly may be because of asthma, comorbid conditions, psychosocial and financial factors and poor family support. This is similar to study by Enright ${ }^{14}$. Statistically significant differences in elderly and young for depressive symptoms, fatigue, emotional well being and impairment of social functioning were similar to other studies. ${ }^{8,15}$

Continued inhalational treatment is important because of growing evidence that persistent airway inflammation predisposes to airway remodeling causing fibrosis and irreversible airflow obstruction. 
This risk increases with duration of asthma and age, stressing need for anti inflammatory medications (inhaled steroids) in elderly. Despite clinical stability on hospitalization, persistent airway inflammation necessitates usage of controller medications to prevent relapse.

During first follow up at $15^{\text {th }}$ day, all patients had already been put on inhalational mediations. Both groups showed improvement in symptoms, compliance, technique of inhalation and PEFR.

During $2^{\text {nd }}$ followup at $1^{\text {st }}$ month, allelderly and young improved symptomatically with improvements in lung functions. Compliance fell from a previous of $68 \%$ amongst elderly to $48 \%$ and rose from $86 \%$ to $90 \%$ amongst young necessitating requirement of continued follow ups, especially in elderly. Technique of inhalation also improved in both groups stressing need of demonstration of device usage at follow up visits. The adverse effect profile also fell down further. There was no admission.

During follow up at $2^{\text {nd }}$ month, symptomatic profile, compliance, drug delivery techniques and mean PEFR further improved. No patient complained of adverse effects due to inhalational medications. However, 7 patients amongst elderly and 1 amongst young were put on only oral medications because of cost. Also, 3 elderly were admitted for the worsening of the disease, while there was no admission amongst young.

During follow up at $3^{\text {rd }}$ month, symptomatic improvement was seen in 94\% elderly and 96\% young and none were admitted for exacerbations. Compliance further improved however, adverse effect profile deteriorated showing that oral medications are associated with a poorer adverse effect profile. Technique of inhalation was checked amongst all patients, irrespective of the fact that whether they were on inhalational medication or not and it was found that it further improved with improvements in mean PEFR as well.

Limitations of the study: Allergic rhinitis was not studied as a comorbidity. Also, though the sample size and follow up period was adequate, had these been even greater, the differences would have got further reflected.

\section{CONCLUSIONS}

It can be concluded that there is significant difference between elderly and young asthmatics, right from the presentation to the final outcomes. This includes differences in symptomatic profile, history of atopy, severity of disease, baseline lung function tests and management parameters including the treating physician, routes of drug delivery, compliance with medications and confidence and technique of taking inhalational medications. There are also differences in psycho social profile, presence of living spouse, family support and quality of life indicators. Elderly are likely to have significant comorbid conditions and higher number of drug usage. Thus there is under-diagnosis at first stage. Once diagnosed, it is undertreated because of physician concerns regarding availability and safety of various medications, problems with compliance and various psycho social and economic factors.

Physicians need to be made aware of these parameters and the differences between young and elderly. There must be continued motivations by the physician for improving compliance and friendly discussions are a must with a good patient-doctor relationship to improve final outcomes of disease, especially in elderly. Since patients managed by pulmonologist fared better as compared to primary care physicians, quacks and alternate system of medication, so the latter group need to be educated regarding asthma guidelines and practice them properly.

\section{REFERENCES}

1. Savage B A. Lung disease and asthma severity in adults with asthma: data from the Third National Health and Nutritional Examination. J Asthma 2005;42:519-23.

2. Braman SS, Hanania. NA Asthma in Older Adults. Clinics In Chest Medicine 2007;28:685-702.

3. Diette GB, Krishnan JA, Dominici F. Asthma in Older Patients. Arch Intern Med 2002;162:1123-132. 
4. Quadrelli SA, Roncoroni AJ. Is Asthma in the Elderly Really Different? Respiration 1998;65:347-353.

5. Parameswaran K, Hildreth AJ, Chadha D, Keaney NP, Taylor IK, Bansai SK. Asthma in the elderly: underperceived, underdiagnosed and undertreated; a community survey. Respir Med1998;92:573-7.

6. Weiner $\mathrm{P}$, Magadle $\mathrm{R}$, Waizman $\mathrm{J}$, Weiner $\mathrm{M}$, Rabner M, Zamir D. Characteristics of asthma in the elderly. Eur Respir J 1998;12:564-68.

7. Burrows $B$, Barbee RA, Cline MG, Knudson RJ, Lebowitz MD. Characteristics of Asthma among Elderly Adults in a Sample of the General Population. Chest 1991;100:935-42

8. Barr RG, Somers SC, Speizer FE, Camargo CA. Patient Factors and Medication Guideline Adherence among Older Women with Asthma. Arch Intern Med. 2002;162:1761-8.

9. Sin DD, Tu JV. Underuse of Inhaled Steroid Therapy in Elderly Patients with Asthma. Chest 2001;119:720-5.

10. Pereira LMP, Clement $Y$, Silva CKD, Mclntosh D, Simeon DT. Understanding and Use of Inhaler Medication by Asthmatics in Specialty Care in Trinidad: A Study Following Development of Caribbean Guidelines for Asthma Management and Prevention. Chest 2002;121:1833-40.
11. Cochrane MG, Bala, MV, Downs KE. Inhaled cortico steroids for asthma therapy : patient compliance devices, and inhalation technique. Chest 2000:117:542-50.

12. Adams RJ, Wilson DH, Taylor AW, Daly A, Espaignet ET, Grande ED, Ruffin RE. Coexistent Chronic Conditions and Asthma Quality of Life: A PopulationBased Study. Chest 2006; 129:285-291

13. Goyal RK. Diseases of the Esophagus. Harrisons Principles of Internal Medicine. McGraw-Hill Companies, Inc. $16^{\text {th }}$ Ed. 2005;2:1742-3.

14. Enright PL, McClelland RL, Newman AB, Gottlieb DJ, Lebowitz MD. Underdiagnosis and Undertreatment of Asthma in the Elderly. Chest 1999;116:603-613.

15. Ng T, Chiam P, Kua E. Mental disorders and asthma in the elderly: a population-based study. International Journal of Geriatric Psychiatry 2006;22:668-74. 